\title{
EXCESSIVE DAYTIME SLEEPINESS AND ITS RELATION WITH QUALITY OF LIFE AND ACADEMIC PERFORMANCE IN MEDICAL STUDENTS
}

\author{
Hafiz Muhammad Sameer ${ }^{\mid 凶}$, Nazish Imran', Taliah Naseer Tarar'
}

\begin{abstract}
OBJECTIVE: To establish a relationship between excessive daytime sleepiness, quality of life (QOL) and academic performance among medical students.

METHODS: This descriptive cross-sectional study was conducted from August to December 2018 on 441 medical students, selected through non-probability convenience sampling from a public-sector university in Pakistan. Data collection tool was a closed ended, self-administered questionnaire, consisting of the Epworth Sleepiness Scale (ESS), WHO Quality of Life-brief version (WHOQOLBREF) scale and demographic information. Questions regarding sleep quality before exam and self-perceived academic performance were also included. Data analysis was done using SPSS version 25 . Pearson correlations and student t-tests were used at a significant level of $p<0.05$
\end{abstract}

RESULTS: Out of 596 questionnaires distributed among students, $44 \mathrm{I}$ students returned the questionnaire with a response rate of $73.9 \%$. The mean age of the study population was $20.56 \pm \mathrm{I} .6 \mathrm{I}$ years. The sample comprised $274(56 \%)$ female and 194 (44\%) male students. Majority of students (37.6\%) had average sleep of 6-7 hours/night. Higher scores on the ESS correlated with lower scores on the WHOQOL-BREF domains and a statistically significant correlation $(p<0.05)$ was obtained between ESS scores and WHOQOL-BREF's physical and psychological domain scores. The study established no significant correlation between daytime sleepiness and self-reported academic performance of medical students.

CONCLUSION: Excessive daytime sleepiness is related to decreased quality of life in medical students. Thus, medical schools should provide necessary support for students to overcome such challenge in order to cope better with their continuous academic demands.

KEY WORDS: Sleep (MeSH); Sleep habits (Non-MeSH); Quality of Life (MeSH); Academic Performance (MeSH); Students, Medical (MeSH).

THIS ARTICLE MAY BE CITED AS: Sameer HM, Imran N, Tarar TN. Excessive daytime sleepiness and its relation with quality of life and academic performance in medical students. Khyber Med Univ J 2020;12(4):299-304. DOI: 10.35845/kmuj.2020.2047I.

\section{INTRODUCTION}

Ex cessive daytime sleepiness (EDS) is difficulty in maintaining a desired level of wakefulness. Many symptoms like psychomotor slowing and closing eyelids for a longer time than for blinking often accompany EDS. ${ }^{1,2}$ Literature suggests that $13 \%$ of the population experience excessive sleepiness. ${ }^{3}$ Recent data also has suggested that excessive daytime sleepiness and its associated wake-state instability has contributed to significant serious functional consequences, including work-related errors and accidents, catastrophic accidents, and motor vehicle accidents. ${ }^{4-8}$ Although, excessive daytime sleepiness affects various aspects of health, this article will focus on its association with medical student's quality of life (QOL) and their
1. Department of Child \& Family Psychiatry, King Edward Medical University / Mayo Hospital, Lahore, Pakistan. Email区: sameer2376@hotmail.com Contact \# : +92-307-4087652

$\begin{array}{ll}\text { Date Submitted: } & \text { June 28, } 2020 \\ \text { Date Revised: } & \text { November 03, 2020 } \\ \text { Date Accepted: } & \text { November 06, 2020 }\end{array}$

academic performance.

Daytime sleepiness is a significant problem and is more common among college students $(50 \%)$ compared to adults (30\%). ' Sixty percent of student's report feeling draggy, sleepy and tired at least 3 days a week. ${ }^{10}$ Various neurobehavioral and cognitive effects of this sleepiness have been identified specifically problems with memory, concentration, learning, and decision making alongside increased risk taking." Impact of inadequate sleep on academic performance has also been noted by a significant proportion (82\%) of medical students. ${ }^{12}$ Alongside stress, sleep problems are ranked by students as a major factor negatively impacting their academic performance. ${ }^{10}$

Although sleepiness or deprivation of sleep has deleterious effects on multiple health domains, this article will focus on how sleepiness can affect $\mathrm{QOL}$ and academic performance of medical students. World Health Organization, described QOL as "individual's perceptions of their position in life, in the context of the culture and value systems in which they live and in relation to their goals, expectations, standards and concerns". ${ }^{3}$ QOL is a multidimensional concept that serves as a reference against which an individual can measure the different domains of one's own life. Medical profession is physically and mentally demanding. Investigating medical students' QOL will give us an insight to their lives, helping us identify and address the needs of 
TABLE I: WHOQOL-BREF GENERAL ITEM FACET SCORES

\begin{tabular}{|c|c|c|}
\hline \multirow[b]{2}{*}{ Variable } & \multicolumn{2}{|c|}{ Respondents } \\
\hline & $\begin{array}{c}\text { ESS }^{5} \text { score } \geq 10 \\
(N=198)\end{array}$ & $\begin{array}{c}\text { ESS score }<10 \\
(\mathrm{~N}=243)\end{array}$ \\
\hline \multicolumn{3}{|l|}{ Overall Quality of life } \\
\hline Very Poor & $9(4.5)$ & $4(1.6)$ \\
\hline Poor & $14(7.1)$ & $6(2.5)$ \\
\hline Neither Poor nor Good & $37(18.7)$ & $47(19.3)$ \\
\hline Good & $103(52.0)$ & $140(57.6)$ \\
\hline Very Good & $35(17.7)$ & $46(18.9)$ \\
\hline \multicolumn{3}{|l|}{ Health Satisfaction } \\
\hline Very dissatisfied & $14(7.1)$ & II (4.5) \\
\hline Dissatisfied & $42(21.2)$ & $28(11.5)$ \\
\hline Neither Satisfied nor dissatisfied & $52(26.3)$ & $63(25.9)$ \\
\hline Satisfied & $76(38.4)$ & $120(49.4)$ \\
\hline Very Satisfied & $14(7.1)$ & $21(8.6)$ \\
\hline
\end{tabular}

TABLE II: QOL-BREEF DOMAIN SCORES BASED ON EXCESSIVE DAYTIME SLEEPINESS STATUS ${ }^{\#}$

\begin{tabular}{l|l|c|c|c|}
\hline QOL-BREF Domains & $\begin{array}{c}\text { ESS score } \geq 10 \\
\mathbf{( N = 1 9 8 )}\end{array}$ & $\begin{array}{c}\text { ESS score < I0 } \\
\mathbf{( N = 2 4 3 )}\end{array}$ & F & p-value \\
\hline Physical health & $56.18 \pm 15.45$ & $62.73 \pm 15.20$ & 0.53 & $0.00^{\$}$ \\
\hline Psychological health & $52.44 \pm 18.10$ & $57.54 \pm 15.87$ & 2.58 & $0.00^{\$}$ \\
\hline Social relationships & $57.94 \pm 20.29$ & $59.03 \pm 18.14$ & 3.04 & $0.55^{\$}$ \\
\hline Environment & $61.52 \pm 14.49$ & $63.88 \pm 13.25$ & 4.01 & $0.07^{\$}$ \\
\hline
\end{tabular}

medical students and to develop different strategies like counseling and mentoring services, educational reforms and student wellness programs. Improving medical student's QOL will generate a competent crop of future doctors and will benefit patients and public health sector in long run.

Therefore, this study was conducted to demonstrate a relationship between the self-perceived sleepiness, QOL and academic performance of medical students, using the Epworth Sleepiness scale (ESS), ${ }^{14}$ WHO Quality of Life-brief version (WHOQOL- BREF) scale ${ }^{15}$ and questions on self-perceived academic performance.

\section{METHODS}

This cross-sectional study was conducted at a public-sector university in Pakistan from August to December 2018 through Non-probability convenience sampling technique. After written informed consent, a sample of 44I medical students from first year to final year completed the data collection form. The data collection tool was a closed ended, self-administered questionnaire, which included the ESS, WHOQOL- BREF scale, General Health Questionnaire (GHQ)-I2, questions on sleep quality before exam, self-perceived academic performance and demographic information like age (years), sex (male, female), residence ( home, hostel, private accommodation), average sleep time and year in medical school. Additional information on the use of regular sleeping aids (e.g., sleeping pills) and use of caffeinated drinks per day was also included. GHQ and its association with daytime excessive sleepiness is reported elsewhere. ${ }^{16}$

The ESS is a validated scale that assesses the likelihood of the subject to fall asleep during certain activities.' 4 It comprises 8 questions on various situations commonly encountered in daily life, and the subjects must rate their chances of falling asleep during these situations. The responses range from 0 (would never fall asleep) to 3 (high chance of falling asleep) based on the subject's recent lifestyle. ESS scores are obtained by adding the scores of all 8 questions. ESS scores ranges from 0 to 24 and is interpreted as within normal limits (ESS $<10$ ) or as suffering from excessive daytime sleepiness $(E S S \geq 10) .{ }^{10}$

The WHOQOL-BREF scale 15 contains a total of 26 questions, with one item from each of the 24 facets of WHOQOL-I00. Two more items have been included from the Overall QOL and General Health facet. These 2 items inquire about an individual's overall perception of quality of life and perception of health. An individual's perception of quality of life in physical, psychological, social relationship and environmental domain are scored. Higher scores in domains denote higher QOL. Domain scores are calculated based on mean score of items within each domain. With a view to make domains cores comparable with the scores used in the WHOQOL-100, mean scores are multiplied by 4 .

The academic performance was evaluated by including two additional questions asking students to rate their sleep quality before exam and selfperceived academic performance as excellent, good, satisfactory, poor and very poor.

Institutional Review Board of King Edward Medical University approved the study (Reference \# 95/RC/KEMU). Participation in the study was entirely voluntary and confidentiality of the study participants was ensured.

The data was analyzed using SPSS for Windows version 25.0. The reliability of ESS and WHOQOL-BREF scale was determined through internal consistency by applying Cronbach's $\alpha$ test. The $\alpha$ value was set at 0.05 . Descriptive statistics were calculated for the full dataset. Mean $\pm S D$ are determined for continuous variables and compared using independent sample t-test. For categorical variables, the number and percentages of students in each category were calculated and $\mathrm{Chi}^{2}$ test was used to compare independent groups. p- 
value $<0.05$ was considered as statistically significant.

\section{RESULTS}

A sum of $44 \mathrm{I}$ students (among 596 questionnaires distributed) returned the questionnaire, resulting in $73.9 \%$ response rate. The mean age of the study population was $20.56 \pm 1.61$ years. The sample comprised $56 \%$ (274) female and 44\%(194) male students. Students from all years of medical education were included in the study. Almost $63.9 \%$ (282) were residing in hostels. Majority of students $(37.6 \%)$ had average sleep of 6-7 hours/night.

The Cronbach coefficient expressed the degree of internal consistency among the items of the questionnaire. The Cronbach coefficient of the ESS and WHOQOL-BREF scale were 0.69 and 0.82 respectively.
A total of $44.9 \%(n=198)$ of students in our sample were sleepy during the day (ESS score $\geq 10$ ) and mean ESS score of whole study sample was $9.39 \pm 3.94$. Also, $121(61.1 \%)$ women and 77 (38.9\%) men scored $\geq 10$ on the ESS. 16

The mean $\pm S D$ WHOQOL-BREF domain scores of all respondents for physical health, psychological health, social relationships and environmental domains were $59.79 \pm 15.64$, $55.25 \pm 17.08,58.54 \pm 19.12$ and $62.82 \pm 13.85$, respectively. Among all respondents, 140 students (57.6\%) with ESS $<10$ rated their overall quality of life to be 'Good', with 120 students $(49.4 \%)$ rated their health as 'satisfied'. However, 103 students (52.0\%) with ESS $\geq 10$ rated their overall quality of life to be 'Good', with only 76 students (38.4\%) rated their health as 'satisfied'. These results are summarized in table $I$.

In terms of domain scores, the study showed individual domain scores in ESS controls (ESS score $<10$ ) to be significantly lower than in ESS cases (ESS score $\geq 10$ ). The mean scores of each WHO QOL-BREF domain (physical, psychological, social relationship and environmental) for ESS cases (ESS score $\geq 10$ ) and ESS controls (ESS score $<10$ ) are shown in table II. When analyzed it was found that Excessive Daytime Sleepiness had a significant impact $(p<0.05)$ on physical and psychological domain scores of QOL, while, social relationship and environmental domain scores were not significantly affected by excessive daytime sleepiness ( $p>0.05)$. Comparison between mean domain scores is shown in figure $\mathrm{I}$.

Comparative analysis of each domain of QOL-BREEF, based on the demographic statistics of the study group, showed that on average, females scored lower in all domains of $\mathrm{QOL}$ as compared to males except for the social domain. Other characteristics of the study group that were associated with

TABLE III: QOL-BREEF DOMAIN SCORES BASED ON DEMOGRAPHIC STATISTICS ${ }^{*}$

\begin{tabular}{|c|c|c|c|c|c|}
\hline Variable & $\begin{array}{c}\text { Study Participants } \\
{[\mathrm{n}(\%)]}\end{array}$ & Physical domain & $\begin{array}{c}\text { Psychological } \\
\text { domain }\end{array}$ & Social domain & $\begin{array}{c}\text { Environmental } \\
\text { domain }\end{array}$ \\
\hline \multicolumn{6}{|l|}{ Sex } \\
\hline Female & $247(56)$ & $57.63 \pm 15.55$ & $54.21 \pm 16.51$ & $61.69 \pm 15.81$ & $63.17 \pm 13.47$ \\
\hline Male & $194(44)$ & $62.54 \pm 15.35$ & $56.58 \pm 17.73$ & $54.54 \pm 22.04$ & $62.38 \pm 14.35$ \\
\hline \multicolumn{6}{|l|}{ Year of medical school } \\
\hline First year & $96(21.8)$ & $57.03 \pm 17.12$ & $55.22 \pm 19.89$ & $58.25 \pm 21.64$ & $61.76 \pm 14.52$ \\
\hline Second year & $95(21.5)$ & $53.87 \pm 15.63$ & $52.29 \pm 16.21$ & $52.81 \pm 20.85$ & $59.54 \pm 14.76$ \\
\hline Third year & $79(17.9)$ & $61.66 \pm 15.40$ & $52.61 \pm 16.67$ & $58.08 \pm 18.15$ & $62.75 \pm 15.25$ \\
\hline Fourth year & $96(21.8)$ & $64.80 \pm 13.72$ & $59.52 \pm 16.84$ & $62.45 \pm 16.43$ & $66.55 \pm 11.62$ \\
\hline Fifth year & $75(17.0)$ & $62.43 \pm 13.33$ & $56.36 \pm 13.84$ & $61.68 \pm 15.93$ & $63.64 \pm 11.89$ \\
\hline \multicolumn{6}{|l|}{ Residence } \\
\hline Home & $156(35.4)$ & $59.04 \pm 15.82$ & $54.40 \pm 17.17$ & $57.87 \pm 19.67$ & $65.63 \pm 13.87$ \\
\hline Hostel & $282(63.9)$ & $60.28 \pm 15.59$ & $55.85 \pm 17.05$ & $58.83 \pm 18.69$ & $61.22 \pm 13.68$ \\
\hline Private accommodation & $3(0.7)$ & $52.33 \pm 9.71$ & $43.67 \pm 12.50$ & $66.67 \pm 34.55$ & $67.00 \pm 3.46$ \\
\hline \multicolumn{6}{|l|}{ Average sleep } \\
\hline$<6 \mathrm{~h} /$ night & $119(27.0)$ & $56.34 \pm 16.16$ & $52.58 \pm 17.56$ & $58.19 \pm 21.99$ & $60.57 \pm 14.77$ \\
\hline 6 to $<7 \mathrm{~h} / \mathrm{night}$ & $166(37.6)$ & $61.13 \pm 13.81$ & $57.08 \pm 15.60$ & $58.63 \pm 18.48$ & $62.88 \pm 13.21$ \\
\hline 7 to $8 \mathrm{~h} /$ night & $106(24.0)$ & $62.40 \pm 15.56$ & $57.14 \pm 16.41$ & $59.03 \pm 17.32$ & $64.28 \pm 13.36$ \\
\hline$>8 \mathrm{~h} /$ night & $50(11.3)$ & $58.02 \pm 18.78$ & $51.52 \pm 20.68$ & $58.06 \pm 17.99$ & $64.88 \pm 14.38$ \\
\hline \multicolumn{6}{|c|}{ Use of regular Sleep Aids (e.g. sleeping pills) } \\
\hline Yes & $12(2.7)$ & $51.83 \pm 11.05$ & $43.67 \pm 23.70$ & $67.17 \pm 20.53$ & $63.75 \pm|8.7|$ \\
\hline No & $429(97.3)$ & $60.01 \pm 15.70$ & $55.58 \pm 16.78$ & $58.30 \pm 19.05$ & $62.79 \pm 13.72$ \\
\hline \multicolumn{6}{|l|}{ Caffeinated drinks } \\
\hline$<$ I cups/day & $276(62.6)$ & $60.70 \pm 15.58$ & $55.95 \pm 16.55$ & $57.95 \pm 19.40$ & $62.77 \pm 14.08$ \\
\hline I-2 cups/day & I3I (29.7) & $58.78 \pm 15.73$ & $55.39 \pm 16.87$ & $59.27 \pm 18.04$ & $62.48 \pm 12.87$ \\
\hline 3-4 cups/day & $23(5.2)$ & $60.48 \pm 13.39$ & $53.26 \pm 19.50$ & $63.39 \pm 19.64$ & $68.96 \pm 12.76$ \\
\hline$>4$ cups/day & II (2.5) & $47.45 \pm 16.34$ & $40.27 \pm 22.10$ & $54.55 \pm 23.74$ & $55.27 \pm 18.33$ \\
\hline
\end{tabular}


100

90

80

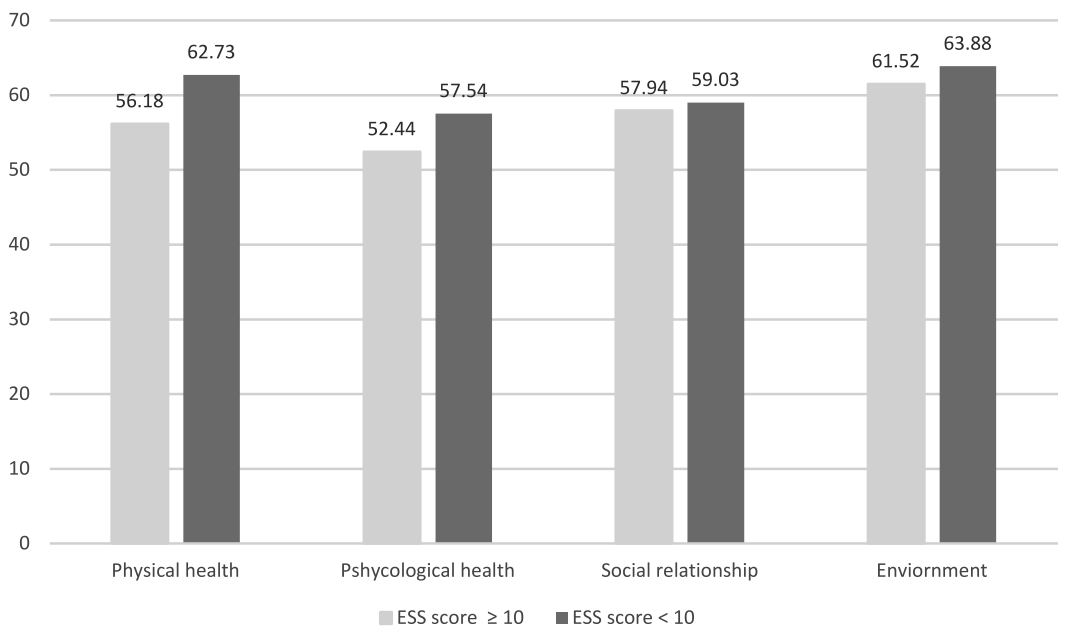

Figure I: Comparison between QOL-BREF ${ }^{\#}$ domain scores of ESS* cases and ESS controls \#WHO Quality of Life-brief version; "Epworth Sleepiness Scale

lower QOL domain scores included studying in second year of medical school, less than 6 hour of sleep at night and more than 4 cups of caffeinated drinks per day. These results are summarized in table ll.

Among the study group, students with ESS score $\geq 10$ rated their sleep quality before an exam to be 'Excellent $=15$ $(7.6 \%)$, Good $=31$ ( $15.7 \%)$, Satisfactory $=58$ (29.3\%), Poor $=59$ $(29.8 \%)$ and Very poor = 35 (I7.7\%)'; while, students with ESS score $<10$ rated their sleep quality before an exam to be 'Excellent $=1$ I (4.5\%), Good = $48(19.8 \%)$, Satisfactory $=85$ (35.0\%), $67(27.6 \%)$ and Very poor $=32$ (I3.2\%)'. Moreover, students with ESS score $\geq 10$ evaluated their academic performance to be 'Excellent $=9$ $(4.5 \%)$, Good $=29(14.6 \%)$, Satisfactory $=120(60.6 \%)$, Poor $=27$ $(13.6 \%)$ and Very poor = $13(6.6 \%)$; while, students with ESS score $<10$ evaluated their academic performance to be 'Excellent $=1 \mathrm{I}$ (4.5\%), Good = $55(22.6 \%)$, Satisfactory $=137$ (56.4\%), Poor $=33$ (I3.6\%) and Very poor $=7(2.9 \%)^{\prime}$. Comparison between the two groups, showed that excessive daytime sleepiness does not have a significant impact on sleep quality $(p>0.05)$ and self-perceived academic performance $(p>0.05)$ of medical students

\section{DISCUSSION}

This study established that excessive sleepiness during daytime is significantly associated with poor QOL. Overall, higher scores on the ESS were correlated with lower scores on the WHOQOL-BREF domains. The results are like another study conducted on academic and private practice physicians, which also showed a significant correlation between high ESS scores and low WHOQOL-BREF domains scores. ${ }^{17}$ Hence, our study establish that the status of Excessive Daytime Sleepiness is linked with a poor QOL.

In terms of domain scores, our study showed excessive daytime sleepiness had a significant impact $(p<0.05)$ on physical and psychological domain scores of QOL-BREEF, with no significant impact on social relationship and environmental domains scores $(p>0.05)$. While in a previous study conducted on general population, excessive daytime sleepiness was observed to have an adverse impact on physical and social domain. ${ }^{18}$ Other studies done on this issue reported medical students to have poorer quality of life than other young adults. ${ }^{19}$. To the best of our knowledge much less work has been done in finding the causes of poorer quality of life among medical students and in an attempt to do so we studied the impact of demographic statistics of the study group on the QOL domain scores and compared them with ESS score.

Our study showed females had low mean scores in all domains except social domain, when compared with males. A similar study done on Chinese population showed the same results where females also had lower scores in all domains except social domain scores. ${ }^{20}$ But, another study done on Indian medical students showed opposite results where females had better quality of life than males and had higher scores in all domains except physical domain. ${ }^{21}$ In relation to EDS, $60.3 \%$ males in our research were not experiencing excessive daytime sleepiness $(E S S<10)$ and at the same time were scoring higher in WHOQOLBREF domains than females, while 48.9\% females experienced excessive daytime sleepiness and scored lower in WHOQOL-BREF domains. ${ }^{16}$ Thus, high prevalence of EDS among females may explain poor quality of life among them.

Among students of different school years, $4^{\text {th }}$ year students scored highest while $2^{\text {nd }}$ year scored lowest in all QOL domains. This is contrary to a research done on Chinese and Brazilian medical students where $3^{\text {rd }}$ year students scored lowest in all domains, explained by their increased academic courses and clinical exposure in $3^{\text {rd }}$ year. $^{20,22}$ Also, in our study $2^{\text {nd }}$ year students had highest EDS prevalence $(53.6 \%)$ as compared to other years. ${ }^{16}$ Hence, here too, high prevalence of EDS among $2^{\text {nd }}$ year students may explain poor QOL among them.

Similarly, students who slept $<6 \mathrm{~h} /$ night and students who took $>4$ cups of caffeinated drinks per day showed lowest scores in all domains and high prevalence of EDS. ${ }^{16}$ However, students staying in hostels had lower scores only in environmental domain when 
compared with students living at their homes, yet they had higher EDS prevalence. ${ }^{16}$ This co-occurrence of high EDS prevalence with lower QOL domain scores among different demographic groups may explain the relationship of excessive daytime sleepiness with lower QOL among medical students. Thus, our study highlights Excessive Daytime Sleepiness to be one of the probable cause of poor QOL among medical students.

Our study failed to show any significant relationship between excessive daytime sleepiness and academic performance of students. Previous studies done on this subject report excessive daytime sleepiness adversely affects students' academic performance. ${ }^{23}$ The difference might be because in these studies, the assessment of academic performance was based on average of marks obtained by students in their annual exams ${ }^{23}$ while in our study subjective perception of performance in exams by students themselves was utilized to evaluate academic performance rather than their exam scores.

This study provides the basic insight in the lives of medical students, helping us identify and address the needs of medical students and to develop different strategies like counseling and mentoring services, educational reforms and student wellness programs. Improving medical student's quality of life will generate a competent crop of future doctors and will benefit patients and public health sector in long run.

Our study has its own limitations since it was performed with medical students of single public-sector university. Results might vary in other private or even public sector universities. Being crosssectional, the study cannot explain causation, as it is unknown whether disturbed sleep patterns are causing poor QOL and vice versa. Also, sample population included a narrow range of age limit; thus, results can't be generalized. To extrapolate the findings, multicenter studies need to be conducted with a large sample size to draw reliable parametric inferences

\section{CONCLUSION}

To conclude, excessive daytime sleepiness is significantly associated with poor QOL among medical students. Thus, medical schools should provide necessary support for medical students to improve their quality of life.

\section{REFERENCES}

I. Chellappa SL, Araújo JF. Excessive daytime sleepiness in patients with depressive disorder. Braz J Psychiatry 2006 Jun;28(2): 126-9. DOI: $10.1590 / \mathrm{s}$ I 5 I6-4446200 6000200010 .

2. Santamaria J. How to evaluate excessive daytime sleepiness in Parkinson's disease. Neurology 2004 Oct 26;63(8 suppl 3): S2I-3. DOI: 10.1212/WNL.63.8_suppl 3. S2I.

3. D'alessandro R, Rinaldi R, Cristina E, Gamberini G, Lugaresi E. Prevalence of excessive daytime sleepiness an open epidemiological problem. Sleep 1995 Jun; 18(5):38991.

4. Lockley SW, Cronin JW, Evans EE, Cade BE, Lee C], Landrigan CP, et al. Effect of reducing interns' weekly work hours on sleep and attentional failures. N Engl J Med 2004 Oct 28; 35I(I8):1829-37. DOI: 10.1056/ NEJMoa04I 404.

5. Landrigan CP, Rothschild JM, Cronin JW, Kaushal R, Burdick E, Katz JT, et al. Effect of reducing interns' work hours on serious medical errors in intensive care units. N Engl J Med 2004 Oct 28;35I(I8): 1838-48. DOI: I0.I056/NEJMoa04I 406.

6. Dinges DF. An overview of sleepiness and accidents. J Sleep Res $1995 \mathrm{Dec} ; 4(\mathrm{~S} 2): 4-14$. DOI: |0.1।II| j.|365-2869.1995.tb 00220.x..

7. Stutts JC, Wilkins JW, Osberg JS, Vaughn BV. Driver risk factors for sleep-related crashes. Accid Anal Prev 2003 May;35(3):32I-3I. DOI: 10.1016/s000 I-4575(02)00007-6.

8. Barger LK, Cade BE, Ayas NT, Cronin JW, Rosner B, Speizer FE, et al. Extended work shifts and the risk of motor vehicle crashes among interns. N Engl J Med 2005 Jan 13;352(2):125-34. doi: 10.1056/ NEJMoa04 I 40 I.

9. Oginska H, Pokorski J. Fatigue and mood correlates of sleep length in three age-social groups: School children, students, and employees. Chronobiol Int 2006;23(6):131728. DOI: $10.1080 / 0742052060$ 1089349.

10. American College Health Association. American College Health Association: National College Health Assessment II Reference Group Executive Summary, Fall 20II. Hanover, MD: American College Health Association; 201I. [Accessed on: February 20, 2014]. Available from URL: http://www. achancha.org/docs/ACHA-NCHA II_ReferenceGroup_ExecutiveSum mary_Fall20I I.pdf.

II.Durmer JS, Dinges DF. Neurocognitive consequences of sleep deprivation. In Seminars in neurology 2005 Mar (Vol. 25, No. 0I, pp. II 7-129). Copyright(C 2005 by Thieme Medical Publishers, Inc., 333 Seventh Avenue, New York, NY I000I, USA.

12. Hershner SD, Chervin RD. Causes and consequences of sleepiness among college students. Nat Sci Sleep 2014 Jun 23;6:73-84. DOI: 10.2147/NSS.S62907.

13. Programme On Mental Health WHOQOL. Div. Ment. Heal. Prev. Subst. Abus. 1998; (WHO/ $\mathrm{MNH} / \mathrm{MHP} / 98.4$. Rev. I)

14. Johns MW. A new method for measuring daytime sleepiness: the Epworth sleepiness scale. Sleep 199| Dec; | 4(6):540-5. DOI: 10.1093/sleep//4.6.540.

I5. WHOQOL Group. Development of the World Health Organization WHOQOL-BREF quality of life assessment the WHOQOL Group. Psychol Med 1998 May;28(3):55I8. DOI: $10.1017 / \mathrm{s} 003329179$ 8006667.

16. Sameer HM, Imran N, Tarar TN, Khawaja IS. Association of excessive 
daytime sleepiness with psychological distress in medical students. Prim Care Companion CNS Disord 2020 Feb 20;22(I): 19m0253I. DOI: 10.4088/PCC. $19 \mathrm{~m} 02531$.

17. Ozder A, Eker HH. The prevalence of excessive daytime sleepiness among academic physicians and its impact on quality of life and occupational performance. Int J Occup Med Environ Health 20I5;28(4):72I-30. DOI: 10.13075/ijomeh. I896.00367.

18. Szentkiralyi A, Madarasaz CZ, Novak M. Sleep disorders: Impact on daytime functioning and quality of life. Expert Rev Pharmacoecon Outcomes Res 2009 Feb;9(I):49. 64. DOI: $10.1586 / 14737 / 67$.

$$
\text { 9.1.49. }
$$

19. Pagnin D, de Queiroz V. Comparison of quality of life between medical students and young general population. Educ Health (Abingdon) 20I5; 28(3):20912. DOI: 10.4103/1357-6283. 178599.

20. ZhangY, Qu B, Lun S, Wang D, Guo Y, Liu J. Quality of life of medical students in China: A study using the WHOQOL-BREF. PLOS One 20I 2;7(II):e497|4. DOI: 10. |37|/journal.pone.00497|4.

21. Nayak MSDP, Naidu SA, Krishnaveni A, Sreegiri S, Srinivas PJ. Quality of life in medical students of Andhra medical college, Visakhapatnam. Int JHealth Sci Res 20I4 Dec; 4(I2): 39 -
43.

22. Aktekin M, Karaman T, Senol YY, Erdem S, Erengin H, et al. Anxiety, depression and stressful life events among medical students: A prospective study in Antalya, Turkey. Med Educ 200I Jan;35 (I):I2-7. DOI: 10.1046/j.I3652923.2001.00726.x.

23. El Hangouche AJ, Jniene A, Aboudar $S$, Errguig L, Rkain H, Cherti M, et al. Relationship between poor quality sleep, excessive daytime sleepiness and low academic performance in medical students. Adv Med Educ Pract 2018 Sep 7;9:63I-638. DOI: 10.2147/AMEP.SI 62350 meningitis in Greek children. Scand J Infect Dis 20I 2;44(5):337-43. DOI: $10.3109 / 00365548.2011 .639030$.

\section{AUTHORS' CONTRIBUTIONS}

Following authors have made substantial contributions to the manuscript as under:

HMS \& NI: Conception and study design, acquisition of data, drafting the manuscript, approval of final version to be published

TNT: Conception and study design, analysis and interpretation of data, drafting the manuscript, approval of final version to be published.

Authors agree to be accountable for all aspects of the work in ensuring that questions related to the accuracy or integrity of any part of the work are appropriately investigated and resolved.

CONFLICT OF INTEREST

Authors declared no conflict of interest GRANT SUPPORT AND FINANCIAL DISCLOSURE NIL

\section{DATA SHARING STATEMENT}

The data that support the findings of this study are available from the corresponding author upon reasonable request.

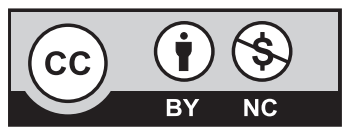

This is an Open Access article distributed under the terms of the Creative Commons Attribution-Non Commercial 2.0 Generic License.
KMUJ web address: www.kmuj.kmu.edu.pk

Email address: kmuj@kmu.edu.pk 